\title{
Rheumatic fever and rheumatic heart disease in Gauteng on the decline: Experience at Chris Hani Baragwanath Academic Hospital, Johannesburg, South Africa
}

\author{
A M Cilliers, MB BCh, FCPaed \\ Paediatric Cardiology Unit, Chris Hani Baragwanath Academic Hospital, Johannesburg, South Africa, and Faculty of Health Sciences, \\ University of the Witwatersrand, Johannesburg
}

Corresponding author: A M Cilliers (antoinette.cilliers@wits.ac.za)

\begin{abstract}
Background. The incidence of rheumatic fever $(\mathrm{RF})$ and its complications has waned over the past three to four decades throughout the Western world, but RF remains a problem in developing countries and in the indigenous populations of some well-resourced countries. A marked decline in children presenting with acute rheumatic fever (ARF) and chronic rheumatic heart disease (RHD) has been observed over the past two decades at Chris Hani Baragwanath Academic Hospital (CHBAH) in southern Gauteng Province, South Africa, which mainly serves the periurban population of Soweto.

Objectives. To analyse the observed decline in ARF and RHD, and consider the reasons for the decrease.

Methods. Review of children with ARF and RHD captured on a computerised database of all children seen in the Paediatric Cardiology Unit at CHBAH during 1993 - 2010.

Results. The records of 467 children with ARF and RHD were retrieved from the database. The majority provided addresses in Gauteng, Soweto and North West Province. The number of children documented to have ARF or RHD declined from 64 in 1993 to 3 in 2010. Onethird of the patients underwent surgery, the majority mitral valve repair. Most of the patients requiring surgery had addresses in parts of Gauteng other than Soweto and other provinces, with relatively few originating from Soweto.

Conclusion. The decline in the number of children with ARF and RHD presenting to CHBAH may be attributed to an improvement in socioeconomic conditions and better access to medical care for the referral population over the past two decades.
\end{abstract}

S Afr Med J 2014;104(9):632-634. DOI:10.7196/SAMJ.8318

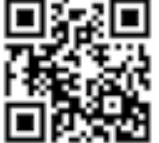

Acute rheumatic fever (ARF) is a delayed complication of pharyngeal infection with a rheumatogenic strain of the group A streptococcus organism, usually occurring in childhood. Devastating complications arising from chronic rheumatic heart disease (RHD) and its associated heart valve damage include severe valve regurgitation, heart failure, strokes and infective endocarditis, usually affecting both younger schoolgoing and economically active, childbearing members of society. The cardiac sequelae pose major medical and surgical challenges in economically deprived regions of the world, where ARF and RHD are most prevalent.

The reduced incidence of ARF in First-World countries is thought to be due to good hygenic conditions and readily available access to healthcare. The introduction of antibiotics has helped to reduce the disease burden, but to a lesser extent than changes in the environment. ${ }^{[1]}$ Although ARF and RHD have become rare in developed countries, pockets of the disease persist among the indigenous populations of prosperous countries such as New Zealand and Australia. The high incidence is thought to be related to poverty, overcrowding, an increased frequency of sore throats and skin infections, and poor access to medical care for the indigenous people in these countries. ${ }^{[2]}$ The last published epidemiological study of RHD in schoolchildren in South Africa was undertaken 30 years ago in 1972 by McClaren et al. ${ }^{[3]}$ who reported a very high prevalence of 6.9/1 000 in schoolchildren in Soweto, Johannesburg. A more recent echocardiographic screening programme in school-aged children using clinical criteria of a pathological murmur and definite RHD diagnosed using echocardiography showed the highest incidence in New Zealand of 7.6/1 000, with lower prevalences of 4.9/1 000 in Uganda, 2.3/1 000 in Mozambique and 0.9/1 000 in India. ${ }^{[4]}$

The incidence of ARF is not well studied on the African continent. ${ }^{[5]}$ The estimated incidence in some developing countries is thought to exceed 50/100 000 children. The explosion of ARF in the Pacific Island areas and Australia has revealed extraordinarily high rates of $80-100 / 100000$ in the indigenous population of New Zealand and 245 - 351/100 000 in Aborigine children in central and northern Australia. ${ }^{[6]}$

A study undertaken in 2006 and 2007 by the Adult Cardiology Unit at Chris Hani Baragwanath Academic Hospital (CHBAH), Soweto, which deals with patients older than 14 years, showed a high incidence of new patients (23.5/100 000) presenting with RHD for the first time. ${ }^{[7]}$ In contrast, there has been a noticeable decline of ARF and RHD among children under the age of 14 years at the same hospital over the past two decades. Although the hospital mainly serves the population of Soweto and patients referred from several secondary hospitals in southern and eastern Gauteng and North West Province, the perception is that most patients with severe disease requiring open-heart surgery do not originate from these areas. The official referral catchment area for the Paediatric Cardiology Unit at $\mathrm{CHBAH}$ has remained largely unchanged over the past 20 years.

\section{Objective}

To review the observed decline in numbers of children seen at the Paediatric Cardiology Unit at CHBAH with a diagnosis of ARF and RHD and those undergoing corrective valve surgery over the past two decades. 


\section{Method}

Analysis of every child referred to the Paediatric Cardiology Unit from within $\mathrm{CHBAH}$ as well as those referred from outside the hospital over the 17-year period 1993 - 2010 was captured on a computerised database maintained by the author. Demographic data such as age, gender, origin, initial presentation with either ARF or RHD, and surgical intervention were recorded.

\section{Results}

A total of 467 children were referred to the Paediatric Cardiology Unit with ARF or RHD during the years 1993 - 2010. The majority of patients provided addresses in parts of Gauteng other than Soweto, followed by Soweto and North West (Fig. 1).

A marked decline in the numbers of children presenting with ARF or RHD occurred during the study period (Fig. 2). Patients with ARF numbered 207/467 (44.3\%). Twenty-two patients with ARF were seen in 1993 and only three in 2010. One hundred and thirteen patients were female and 94 male (Fig. 3), with no statistical difference between males and females $(p=0.158)$. The remaining children $(260 / 467,55.7 \%)$ were referred with RHD and damaged heart valves. Forty-two were seen in 1993 and none in 2010. Of these patients, 138 were female and 122 male (Fig. 3), with no significant difference between the genders $(p=0.2)$. The male/female ratio was 1.2:1 for both the ARF and the RHD groups. The patients with ARF ranged in age from 4 to 16 years, the youngest being a 4-year-old girl admitted in the mid-1990s with moderate mitral regurgitation, who had an address in eastern Gauteng. The children with RHD ranged in age from 3.8 years (a child from North West) to 14.9 years. A third of the patients (137/467) required open-heart surgery to correct leaking valves, the majority undergoing mitral valve repair (Fig. 4). Eight patients (age range 7 - 14 years) underwent mitral valve balloon angioplasty for treatment of severe mitral stenosis. The average age at surgery was 9.3 years, the youngest patient being a boy who underwent mitral valve repair for severe mitral regurgitation at $4 \frac{1}{2}$ years and was referred from a secondary care hospital in southern Gauteng. Although Soweto is the main drainage area for $\mathrm{CHBAH}$, the majority of the patients who needed surgery originated from outside Soweto and were referred from secondary hospitals in southern and eastern Gauteng and North West, from other provinces such as Limpopo, KwaZulu-Natal and the Eastern Cape, and from surrounding southern African countries such as Zimbabwe and Mozambique (Fig. 5). Despite an increase in referral of patients with HIV infection, especially in the early 2000s (Fig. 6), only three patients, two with ARF and one with RHD, were found to be HIVpositive at the time of presentation.

\section{Discussion}

An analysis of the prevalence of RHD and the incidence of ARF in southern Gauteng is not possible from this retrospective review, because not all children with rheumatic fever (RF)-related illnesses in these areas are referred to CHBAH. Although CHBAH mainly serves the community of Soweto, it also functions as a tertiary care referral hospital for surrounding secondary hospitals in southern and eastern Gauteng and adjacent provinces such as North West. Another factor confounding prevalence and incidence calculations is that patient origins cannot be confirmed, resulting in a documented referral population that may be inaccurate and invalid.

A previous study undertaken between 1993 and 1995 that examined the geographical origins of paediatric patients with RF/RHD referred to three Gauteng academic hospitals (Helen Joseph, Chris Hani Baragwanath and Johannesburg General) showed that $70.2 \%$ of patients with RF/RHD with documented addresses originated from outside

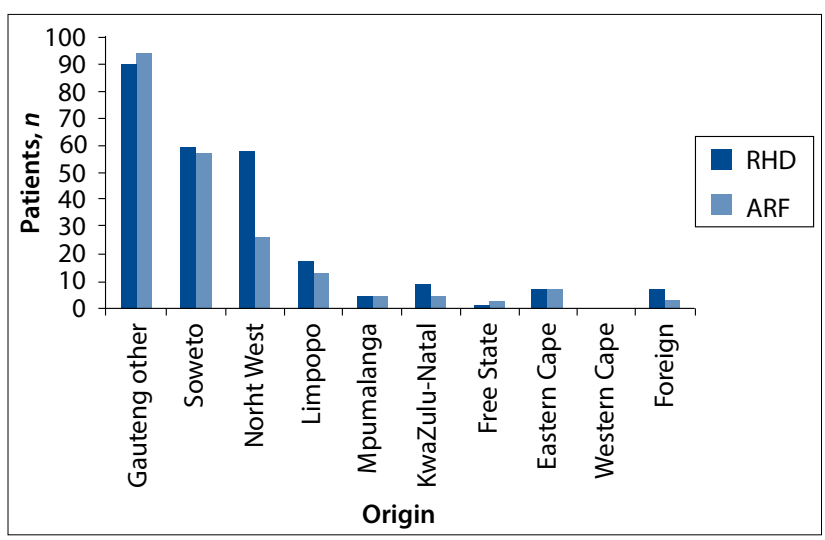

Fig. 1. Origin of patients with RHD and ARF. (RHD = rheumatic heart disease; $A R F=$ acute rheumatic fever.)

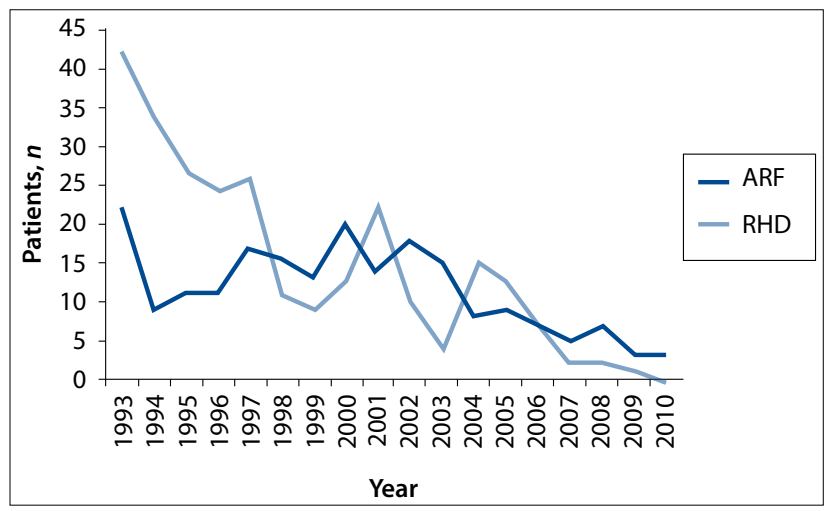

Fig. 2. RHD and ARF trends, 1993 - 2010. (RHD = rheumatic heart disease; $A R F=$ acute rheumatic fever.)

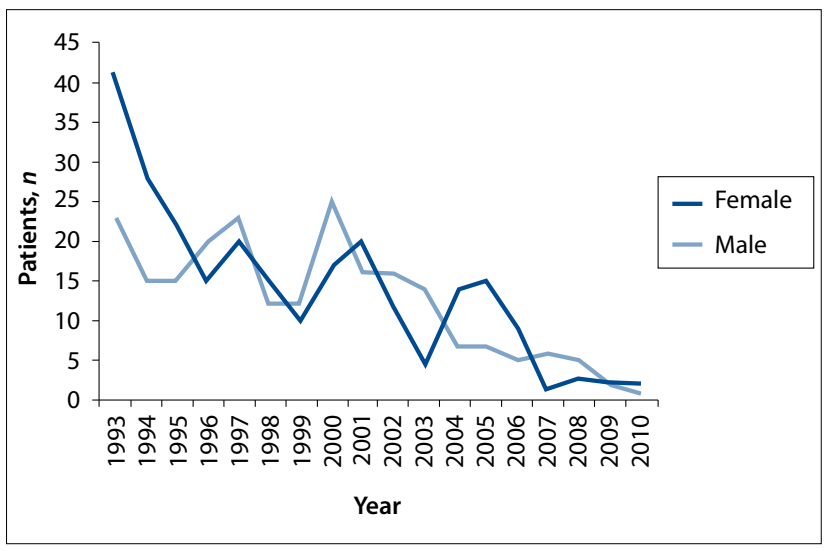

Fig. 3. Males and females presenting with ARF and RHD, $1993-2010$. ( $R H D=$ rheumatic heart disease; $A R F=$ acute rheumatic fever.)

Soweto. The referral catchment areas of the three hospitals were not reported on separately, but grouped together. In addition, the patient age range for the study cohort was not reported. A large proportion of the workload of the three hospitals was derived from patients from outside the borders of Gauteng: 32.7\% were not from Gauteng, and $51 \%$ of these had severe RHD, defined as requiring surgery or balloon valvuloplasty. A third of all the patients (32.9\%) needed surgery or balloon valvuloplasty. The non-Gauteng severe RF/RHD patients were predominantly referred from Northern Province, Mpumalanga, North West and KwaZulu-Natal. ${ }^{[8]}$ The majority of children who were referred for open-heart surgery from CHBAH in this study also did not originate from Soweto; most were referred from secondary hospitals in 
Gauteng and North West, and their origins could not be proven. Severe cases needing heart surgery ( $29 \%$ of all patients) have declined over the 17 years of the study, which may reflect a drop in poverty levels and an increase in the availability of primary healthcare associated with RF prevention programmes provided to the referral population of $\mathrm{CHBAH}$ over the past two decades.

The Census 2011 Statistical Release Document ${ }^{[9]}$ demonstrates an improved trend in the socioeconomic status of SA's population over the past 15 years. There has been an increase in the average annual household income and in access to amenities such as electricity, as well as a decrease in the average household size. This improvement in lifestyle, with less overcrowding, may be an important factor decreasing exposure to the rheumatogenic strains of the streptococcus organism.

The decline in ARF and RHD in children presenting to CHBAH may also be attributed to improved access to healthcare for the general population over the past two decades, and more specifically the introduction of free healthcare to children under the age of 6 years in 1994. ${ }^{[10]}$ Increased access to and availability of penicillin in the primary healthcare setting was found to be effective in reducing the incidence of ARF in Costa Rica ${ }^{[11]}$ and Cuba. ${ }^{[12]}$

Various sociopolitical dynamics could explain the peaks in the numbers of patients with ARF and RHD seen in the early 1990s and early 2000s (Fig. 2). The peak in the 1990s mirrors the civil unrest in the townships, particularly on the Witwatersrand, ${ }^{[13]}$ which marginalised residents and cut off access to medical care, while the peak in the early 2000s may reflect the massive increase in cross-border migration from Zimbabwe, mainly of women, children and the elderly seeking humanitarian assistance. ${ }^{[14]}$ Many of these displaced individuals settled in informal settlements in Gauteng, not disclosing their countries of origin, and making use of medical facilities.

\section{Conclusion}

The number of children presenting to $\mathrm{CHBAH}$ with ARF and chronic RHD has declined dramatically over the past two decades. An improvement in socioeconomic conditions with an increase in household income, better living conditions and less overcrowding, as well as improved availability of medical care, are likely to be contributory factors.

Research approval. Permission to undertake this research was obtained from the Human Research Ethics Committee, University of the Witwatersrand, and the Medical Advisory Committee of CHBAH.

\section{References}

1. DiSciascio G, Taranta A. Rheumatic fever in children. Am Heart J 1980;99(5);635-658. [http://dx.doi. org/10.1016/0002-8703(80)90739-5]

2. White $\mathrm{H}$, Walsh $\mathrm{W}$, Brown A, et al. Rheumatic heart disease in indigenous populations. Heart Lung White H, Walsh W, Brown A, et al. Rheumatic heart disease in indigen
Circ 2010;19(5-6):273-281. [http://dx.doi.org/10.1016/j.hlc.2010.02.019]

3. McLaren MJ, Hawkins DM, Koornhof HJ, et al. Epidemiology of rheumatic heart disease in black schoolchildren of Soweto, Johannesburg. BMJ 1975;3(5981):474-478.

4. Roberts K, Colquhoun S, Steer A, Remenyi B, Carapetis J. Screening for rheumatic heart disease: Current approaches and controversies. Nat Rev Cardiol 2013;10(1):49-58. [http://dx.doi.org/10.1038/ ncardio.2012.157]

5. Tibazarwa KB, Volmink JA, Mayosi BM. Incidence of acute rheumatic fever in the world: A systematic review of population-based studies. Heart 2008;94(12):1534-1540. [http://dx.doi:10.1136/ hrt.2007.141309]

6. Carapetis JR, Steer AC, Mulholland EK, Weber M. The global burden of group A streptococcal diseases. Lancet Infect Dis 2005;5(11):685-694. [http://dx.doi.org/10.1016/S1473-3099(05)70267-X]

7. Sliwa K, Carrington M, Mayosi BM, Zigriadis E, Mvungi R, Stewart S. Incidence and characteristics of newly diagnosed rheumatic heart disease in urban African adults: Insights from the Heart of Soweto newly diagnosed rheumatic heart disease in urban African adults: Insights from the Heat
study. Eur Heart J 2010;31(6):719-727. [http://dx.doi:10.1093/eurheart/eurheart/ehp530]

8. Clur S-A. Frequency and severity of rheumatic heart disease in the catchment area of Gauteng
sturt Clur S-A. Frequency and severity of rheumatic heart
hospitals, 1993-1995. S Afr Med J 2006;96(3):233-237.

9. Statistical Release Census 2011 Product. http://www.statssa.gov.za/census 2011/products.asp (accessed 3 January 2014).

10. Leatte A, Shung-King M, Monson J. Healing inequalities: The free health care policy. South African Child Gauge 2006. http://www.ci.org.za/depts/ci/pubs/pdf/general/gauge2006/gauge2006healing.pdf (accessed 10 March 2014).

11. Arguiedas A, Mohs E. Prevention of rheumatic fever in Costa Rica. J Pediatr 1992;121(4):569-572. [http://dx.doi.org/10.1016/S0022-3476(05)81146-1]

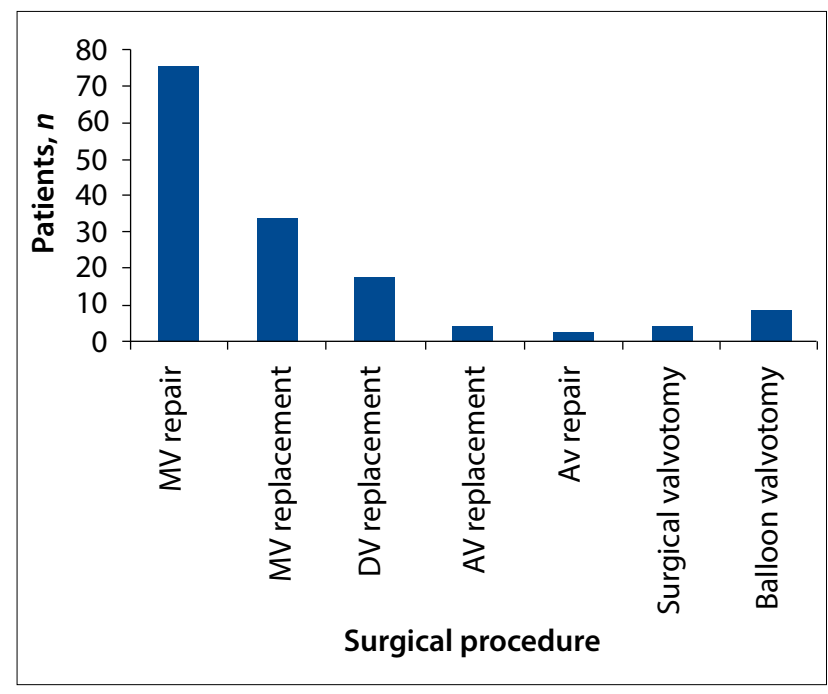

Fig. 4. Types of surgical procedure done, 1993 - 2010. (MV = mitral valve; $D V=$ double valve; $A V=$ aortic valve.)

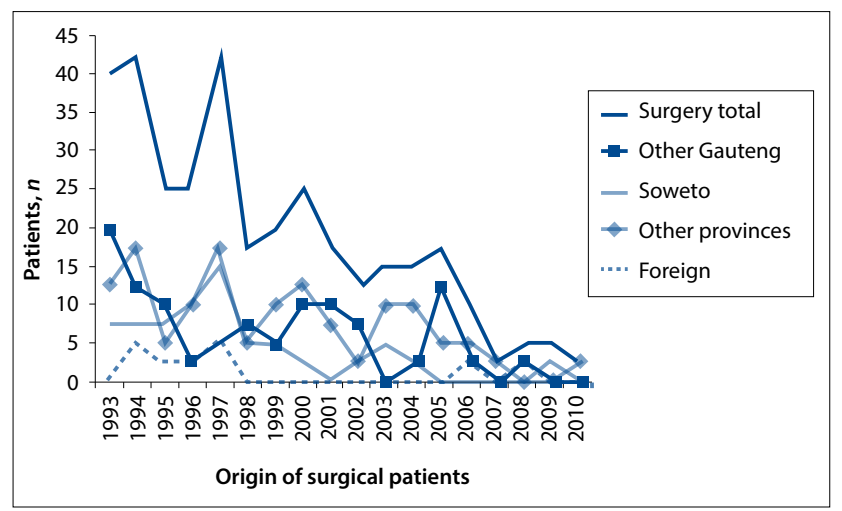

Fig. 5. Origin of patients undergoing surgery for RHD, 1993 - 2010. (RHD = rheumatic heart disease.)

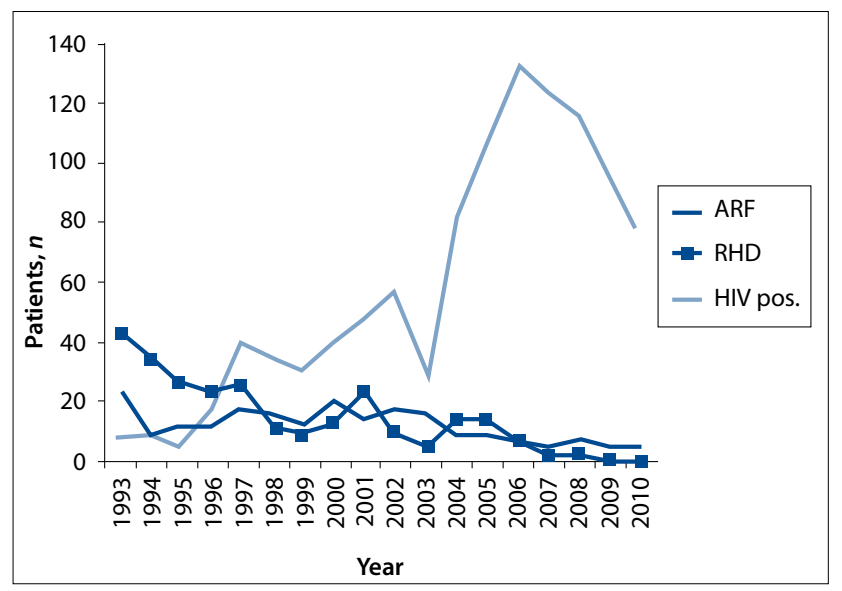

Fig. 6. ARF and RHD v. HIV-infected patients, 1993 - 2010. (RHD = rheumatic heart disease; $A R F=$ acute rheumatic fever; HIV pos. = HIV-positive.)

12. Nordet P, Lopez R, Duenas A, Sarmiento L. Prevention and control of rheumatic fever and rheumatic heart disease: The Cuban experience (1986-1996-2002). Cardiovasc J Afr 2008;19(3):135-140.

3. Kynoch G. Reassessing transition violence: Voices from South Africa’s township wars, 1990-4. Afr Aff (Lond) 2013;112(447):283-303. [http://dx.doi.org/ 10.1093/afraf/adt014]

14. Ngwato Polzer T. South African Government and Civil Society Responses to Zimbabwean Migration (SAMP Policy Brief No. 22). 2008. http://www.migration.org.za/person/tara-polzer-ngwato (accessed 3 January 2014).

Accepted 13 May 2014 